\title{
Performance of concrete blended with pozzolanic materials in marine environment
}

\author{
Asad-ur-Rehman Khan ${ }^{1, *}$ \\ ${ }^{1}$ NED University of Engineering and Technology, Karachi-75270, Pakistan
}

\begin{abstract}
Reinforced concretes structures located at or near the coast line needs to be repaired more frequently when compared to structures located elsewhere. This study is continuation of previous studies carried out at the Department of Civil Engineering, NED University of Engineering and Technology, Karachi, Pakistan to study the performance of concrete made up of cements blended by pozzolonic materials. Different pozzolanic materials (blast furnace slag, fly ash and silica fume) were used in the study. Tests conducted during the study to compare the performance of samples cast from concrete of different mix designs were Compressive Strength Test (ASTM C 39), Flexural Strength Test (ASTM C 293), Rapid Migration Test (NT Build 492), Absorptivity of the oven-dried samples (ASTM C 642) and Half Cell Potential (ASTM C 876). Use of cements blended with pozzolanic materials, used during the study, proved to be effective in enhancing the performance of the concrete exposed to marine environment. Use of pozzolans in concrete not only provides a sustainable and feasible solution to the durability problems in coastal areas, it also helps in conservation of natural resources and reduction of pollution and energy leading to a green environment.
\end{abstract}

\section{Introduction}

Deterioration of reinforced concrete $(\mathrm{RC})$ structures in coastal areas has been one of the major concerns for civil engineers. Huge amount of money is being spent annually in rehabilitation and repair of these deteriorated RC structures. Failure of construction materials to sustain their due performance against environmental aggressions is largely responsible of these unwanted distresses. Role of the oceanic aggressive agents become highly undermining in marine environment. The deterioration of $\mathrm{RC}$ in marine environment, that may be shore decks, bridges, piles, piers or any other RC structure built in coastal areas, is predominantly because of exposure to sea water. The cost of repairing replacing deteriorated structures has become a major liability for users and different agencies.

Most of the onshore structures are constructed with normal carbon steel reinforcement due to it being economical compared to stainless steel or galvanic protection alternatives. Before the actual degradation of concrete corrosion of reinforcement bar is driven up majorly due to carbonation and chloride attack [1]. This results in the loss of alkalinity in concrete around the reinforcement bars leading to the initiation of actual corrosion.

\footnotetext{
* Corresponding author: asadkhan@neduet.edu.pk
} 
For most of the structures exposed to marine environment the major extent of chlorides in concrete originates from the external sources. The penetration of this chloride occurs through various transport mechanisms depending upon the exposure conditions. In the case seawater exposure particularly, the chloride poses a much, in fact the sole, threat to steel in concrete than sulfate do to concrete as calcium sulpho-aluminate or ettringite (the expansive product of sulfate and tri-calcium aluminate in the cement) is more soluble in the presence of chloride and hence it does not initiate a considerable disruptive expansion.

A significant function for durability indexes is the water to cement ratio, lesser the pores, denser the microstructure, lesser penetration of water and ionic aggression and in turns lesser chance of deterioration. Another renowned way of mitigating the degradation of concrete, under the attack of ions, is the replacement of OPC by supplementary cementitious materials like fly ash, slag and silica fume as explained by Philip et al. [2]. These fine particles of pozzolans help in densely packing up the pores leading to permeation and also give rise to formation of excess ultra-stable calcium-silicate-hydrate (C-S-H) through pozzolanic reaction.

Corrosion inhibitors like calcium nitrate can be used in reinforced concrete which does not actually stop corrosion, but delays its initiation. Air-entrainers reduce the probability of segregation and bleeding, ensuring a uniform paste of concrete and improving durability. External waterproofing membranes can also be used to hinder the penetration and absorption of water to a great extent. Membrane system can be categorized as asphalt-impregnated fabric, cementitious, polymer, elastomeric and asphalt-laminated. The initiation of corrosion of steel reinforcement can also be delayed by coating the reinforcement bar with the referenced anodic zinc. Zinc has more electronegative potential than steel that means it is more sensitive to corrosion.

This study is continuation of previous studies carried out at the Department of Civil Engineering, NED University of Engineering and Technology, Karachi, Pakistan ([3-5]) to study the performance of concrete made up of cements blended by pozzolonic materials along with calcium nitrate dosing and external waterproofing applications, exposed to marine environment. Performance of different mix designs was determined by conducting Compressive Strength Test (ASTM C 39 [6]), Flexural Strength Test (ASTM C 293 [7]), Rapid Migration Test (NT Build 492 [8]), Absorptivity of the oven-dried samples (ASTM C 642 [9]) and Half Cell Potential (ASTM C 876 [10]). Results showed that in almost all cases, use of cements blended with pozzolanic materials resulted in an enhanced performance of the concrete exposed to marine environment.

\section{Experimental programme}

Nine different mix designs were used in the study in order to fulfill the scope of studying the performance of marine concrete enhanced by the addition of pozzolans like fly ash, silica fume and slag, along with the use of corrosion inhibitor (calcium nitrate). Details of mix designs are shown in Table 1 . The water to cement ratio was kept fixed as 0.45 . Proportions of the ingredients were designed as per ACI 211.1 [11], except for mix design A. Mix design A contains the ingredients in 1:2:4 ratio (M15 nominal design), and serves as control mix design as it represents general practice in local construction industry for the construction of general residential buildings. Air entrainer was used in all the mix designs except mix design A. Optimum $4 \%$ dosage of calcium nitrate was added in a mix design. Moreover, for workability and ensuring proper compaction with w/c ratio of 0.45 , high-range water reducing plasticizer was used. For each mix design 0.2 cubic yard concrete was prepared. Minimum cover of $3^{/ /}$was maintained for the reinforcement as per specification of ACI 357 [12]. 
Supplementary cementitious materials used in the study as a replacement of Portland cement in concrete were locally available slag cement containing $30 \%$ slag, Fly ash (ClassC) with the activity index up to $88.72 \%$, and silica fume from BASF Chemicals \& Polymers, MasterLife SF 100. Low water to cement ratio, aimed to make concrete denser and more impermeable, was achieved by the help of High-Range Water Reducer (Type-F) from BASF Chemicals \& Polymers, MasterPozzolith LD10 and Super Plasticizer was used additionally for increasing workability. Maximum size of coarse aggregate used was $3 / 4$ inch, sand passing \#4 sieve was used as fine aggregate. Air entrainer (MasterAir 720) and waterproofing membrane (MasterSeal 550) from BASF Chemicals \& Polymers, were also used in the study.

Table 1. Mix Designs

\begin{tabular}{|l|c|c|c|c|c|c|c|c|c|}
\hline Mix Design & A & B & C & D & E & F & G & H & I \\
\hline Water/Cement Ratio & 0.45 & 0.45 & 0.45 & 0.45 & 0.45 & 0.45 & 0.45 & 0.45 & 0.45 \\
\hline Cement (lb/c.yrd) & 500 & 450 & 460 & 350 & 400 & 360 & 225 & 500 & 500 \\
\hline $\begin{array}{l}\text { Slag } \\
\text { (Replacement by \%) }\end{array}$ & & & & $30 \%$ & & & $27 \%$ & & \\
\hline Slag (lb/c.yrd) & & & & 150 & & & 135 & & \\
\hline $\begin{array}{l}\text { Fly Ash } \\
\text { (Replacement by \%) }\end{array}$ & & & & & $20 \%$ & $20 \%$ & $20 \%$ & & \\
\hline Fly Ash (lb/c.yrd) & $10 \%$ & $8 \%$ & & 100 & 100 & 100 & & \\
\hline $\begin{array}{l}\text { Silica Fume } \\
\text { (Replacement by \%) }\end{array}$ & 225 & 202.5 & 207 & 157.5 & 180 & 162 & 101.3 & 225 & 225 \\
\hline Silica Fume (lb/c.yrd) & 1000 & 1000 & 1000 & 1000 & 1000 & 1000 & 1000 & 1000 & 1000 \\
\hline $\begin{array}{l}\text { Water (lb/c.yrd) } \\
\text { Fine Aggregate } \\
\text { (lb/c.yrd) }\end{array}$ & 2000 & 2000 & 2000 & 2000 & 2000 & 2000 & 2000 & 2000 & 2000 \\
\hline $\begin{array}{l}\text { Coarse Aggregate } \\
\text { (lb/c.yrd) }\end{array}$ & 12 & 12 & 12 & 12 & 12 & 12 & 12 & 12 \\
\hline $\begin{array}{l}\text { Calcium Nitrate (oz) } \\
\text { Micro Air Entrainer }\end{array}$ & & & & & & 40 & 40 & & 500 \\
\hline
\end{tabular}

\subsection{Compressive and flexural strength}

Strength has always been the most important characteristic of concrete along with durability. Reduction in compressive and flexural strengths of all mix designs used in the study was determined by exposing respective specimens to marine environment for 100 days after 28 days of curing in normal conditions. An actual splash zone near the construction site of a Quay wall at the harbor port, by China Harbor Engineering Company Group, was selected as marine environment and strength reduction was determined after 100 days. Concentration of different ions in the marine water samples from China Harbor port is shown in Table 2.

Compressive strength was determined by testing 6 inch diameter cylinders as per ASTM C 39, while flexural strength was determined by testing 24 inch long beams with 6 inch 
square cross-section subjected to three-point bending, in accordance with ASTM C 293. Three (03) samples of each type were cast for testing. A set of samples was maintained in controlled non-aggressive environment, a set was coated with waterproofing membrane layer for exposure in marine environment while a set of sample were exposed to the marine environment without water proofing membrane.

Table 1. Ionic Concentrations present in Sea Water Samples

\begin{tabular}{|c|c|}
\hline Ions & China Harbor Port \\
\hline Sulfate & $27.7 \mathrm{gm} / 10 \mathrm{ltr}$ \\
\hline Sodium & $91.96 \mathrm{gm} / 10 \mathrm{ltr}$ \\
\hline Potassium & $11.65 \mathrm{gm} / 10 \mathrm{ltr}$ \\
\hline Calcium & $12 \mathrm{gm} / 10 \mathrm{ltr}$ \\
\hline Magnesium & $15.32 \mathrm{gm} / 10 \mathrm{ltr}$ \\
\hline Chloride & $254.92 \mathrm{gm} / 10 \mathrm{ltr}$ \\
\hline
\end{tabular}

\subsection{Chloride penetration (R.M.T)}

Chloride induced corrosion in marine reinforced structures is a key mechanism directly affecting the durability of the structure. Thus, it can be used as an effective quantifiable durability index of concrete. Electrically-accelerated chloride penetration testing method, known as Rapid Migration Test (RMT) or Rapid Chloride Migration Test (RCMT), was used in the present study, which quantify the ingression of chloride ions. This test was standardized in 1999 by Nordic Council of Ministers as NT Build 492 (1999).

Specimen of 2 inch thickness and 4 inch diameter were used as defined in NT Build 492. The average depth of the chloride penetration was used for further calculation of Chlorideion Migration Coefficient or Non-Steady State Migration Coefficient $\left(\boldsymbol{D}_{\boldsymbol{n} \mathbf{s} s m}\right)$. The diffusion coefficient was calculated using the simplified formula proposed by NT Build 492 for the Non-Steady State Migration Coefficient $\left(D_{n s s m}\right)$ defined in Eq. 1.

$$
D_{n s s m}=\frac{0.0239(273+T) L}{(U-2) t}\left(x_{d}-0.0238 \sqrt{\frac{(273+T) L x_{d}}{(U-2)}}\right)
$$

Where;

$D_{n s s m}=$ Non-steady state migration coefficient, $\times 10^{-12} \mathrm{~m}^{2} / \mathrm{s}$;

$U=$ absolute value of the applied voltage, $\mathrm{V}$

$T=$ average value of the initial and final temperature in the anolyte solution, $\mathrm{C}$

$L=$ thickness of the specimen, $\mathrm{mm}$

$x_{d}=$ average value of the penetration depths, $\mathrm{mm}$

$t=$ test duration, hour

\subsection{Absorption capacity test}

Absorptivity of samples cast from all the mix designs was determined in accordance with ASTM C642. Specimens were extracted from 4 inches diameter cylindrical samples by slicing them with the help of a water cooled diamond saw. Two (02) inches thick slices were obtained for the test. The water absorbed is simply represented in percentage of the sample's dry weight and calculated by Eq. 2 stated below. 


$$
\% \text { water absorption }=\frac{\left(W_{2}-W_{1}\right)}{W_{1}} \times 100
$$

Where,

$W_{1}=$ Oven dry weight of sample;

$\mathrm{W}_{2}=$ Wet weight of sample after it reaches a constant weight.

\subsection{Corrosion rate rest}

The corrosion potential was measured by the help of copper/copper sulfate electrode. The setup was prepared in accordance with the specifications of ASTM C-876. The specimens were subjected to a chlorine environment of $5 \% \mathrm{NaCl}$ solution. The corrosion potential readings were obtained weekly. The corrosion activity is evaluated in accordance with ASTM C-876. Evaluation criteria suggested by ASTM C876 when Copper/Copper Sulfate electrode is utilized is as follows:

1. If potentials over an area are greater than -0.20 volt, there is a probability greater than 90 percent that no steel corrosion is occurring in the area at the time of measurement.

2. If potentials are in the range of -0.20 to -0.35 volt, corrosion activity of the steel in the area is uncertain

3. If potentials are less than -0.35 volt, there is a probability greater than 90 percent that steel corrosion is occurring in the area at the time of measurement.

\section{Results and discussion}

\subsection{Compressive strength}

Compressive strengths of all mix designs before and after exposure to marine environment are shown in Figure 1. Targeted compressive strength for the mix designs was 5000 psi which was achieved by most of the mix designs except for mix designs involving fly ash, with or without silica fume and slag (E, F and G). This may be attributed to quality of fly ash used in the study, and more experimentations and testing may be needed to account for for the poor performance of mix designs involving fly ash. Enhanced strength of concrete can be noted in mix designs in which cement was replaced by silica fume, $\mathrm{B}$ and $\mathrm{C}$, and blast furnace slag, D. Addition of calcium nitrate in mix design I and air entrainer in mix designs I and $\mathrm{H}$ seems to have no effect on strength as the strengths similar to control mix design were achieved by mix designs $\mathrm{H}$ and $\mathrm{I}$. All the samples showed reduction in compressive strength after exposure of 100 days to marine environment. Performance of mix designs B,C, H and I was better than rest of the mix designs in terms of strength reduction, followed by mix designs E, F, A, D and G. Highest loss of strength was found in Mix design G with all the three pozzolans. Use of Air entrainer appears to have improved the performance in the marine environment as strength reduction in almost all mix designs is smaller than mix design $\mathrm{A}$ except D and G. 
Controlled Environment

घExposed to Marine Environment with Waterproofing Membrane

घExposed to Marine Environment without Waterproofing Membrane

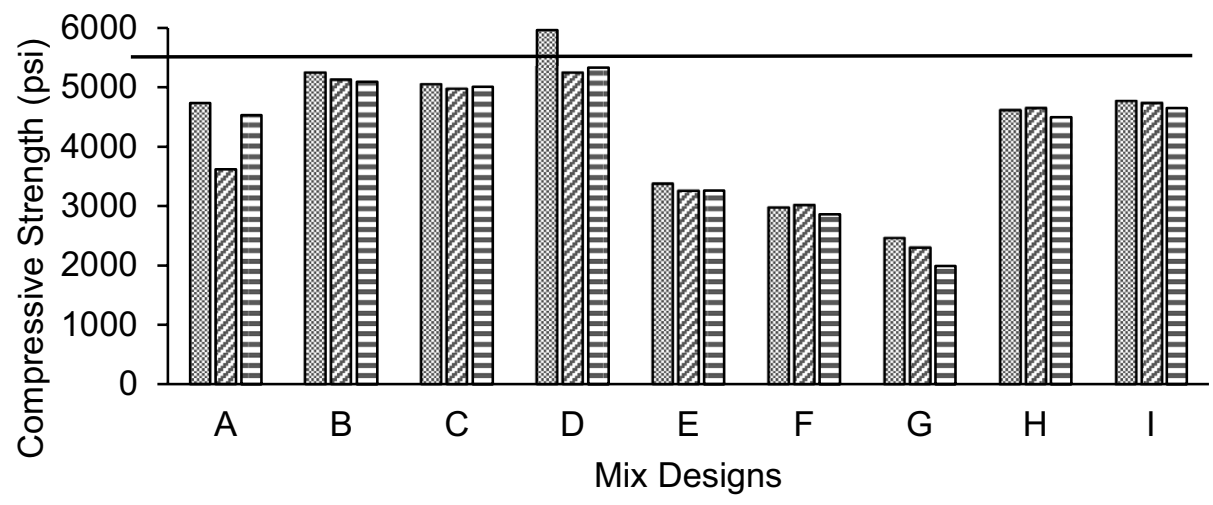

Fig. 1. Compressive Strength Results of Different Mix Designs

\subsection{Flexural strength}

Flexural strengths of all mix designs before and after exposure to marine environment are shown in Figure 2. A trend similar to compressive strength can be seen in Figure 2 that silica fume and slag attributed to the increase in strength while fly ash influenced a considerable loss in flexural strength as well. Mix design D containing 30\% slag showed highest value of strength and least strength degradation in marine exposure. Maximum strength reduction is noted in mix design A. Performance of mix designs $\mathrm{H}$ and I was almost similar. Use of air entrainer and water proofing membrane seems to have contributed in minimizing the loss of flexural strength when exposed to marine environment.

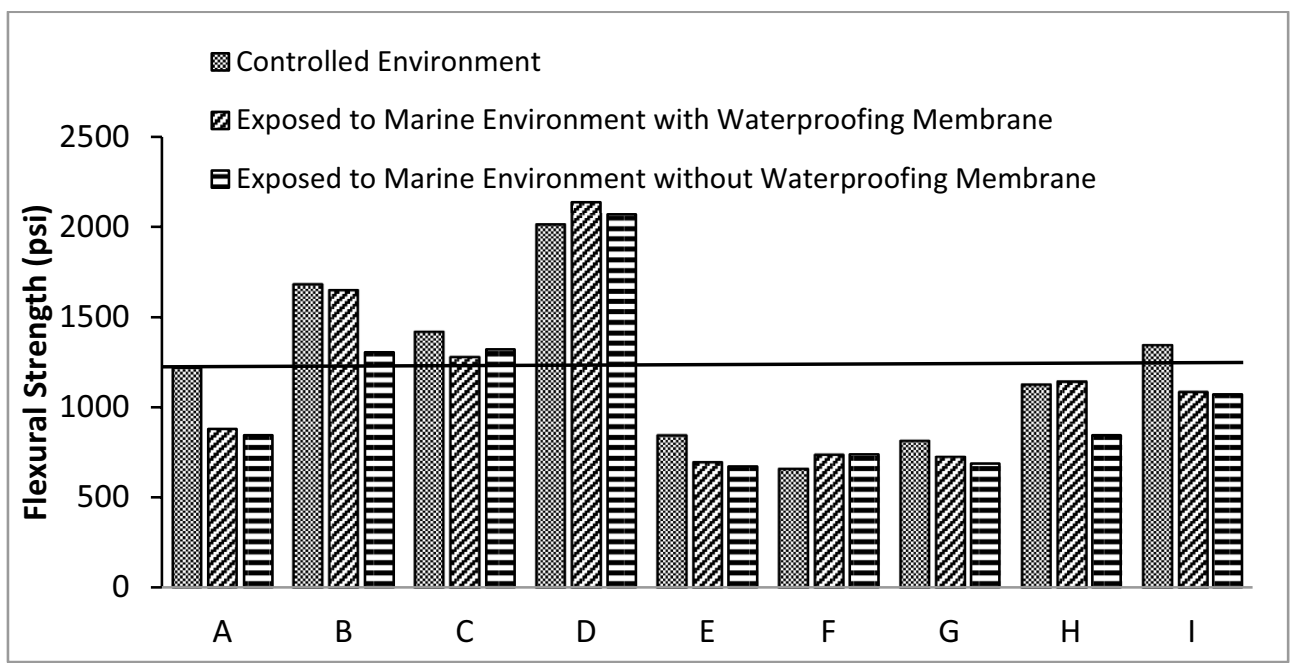

Fig. 2. Flexural Strength Results of Different Mix Designs 


\subsection{Chloride penetration (R.M.T)}

Chloride-ion migration test results of different mix designs are compared in Figure 3. Authenticity and reliability of the results can be justified by the fact that diffusion coefficient of the same mix design did not differ by a wide scale. The slag cement mixes G, D and F, showed a much lower value of diffusion coefficient, than the mixes $\mathrm{A}, \mathrm{H}$ and I containing only OPC. Fly ash and silica fume also contributed to the reduction in the diffusion coefficient's value for B, C and E mix designs. Performance of the mix design G, with fly ash, silica fume and slag, was found to be best against chloride ingression and showed least chloride penetration depth as well. Dosage of calcium nitrate and air entrainer seems to have no effect on providing resistance against chloride ions induced with a potential difference.

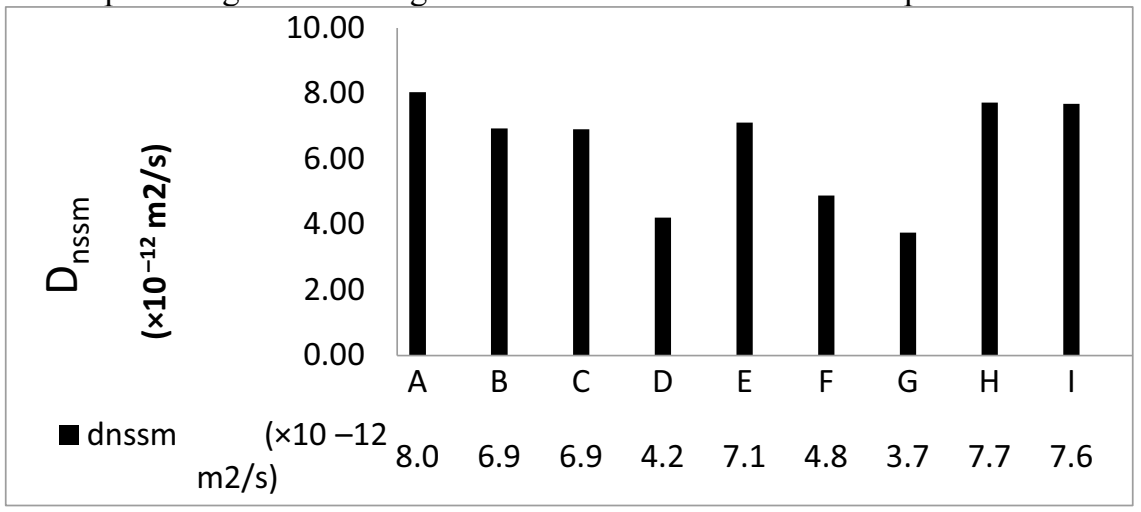

Fig. 3. Chloride Rapid Migration Coefficient Results for Different Mix Designs

\subsection{Absorption capacity test}

Percentage of water absorption of dry specimens by weight as per ASTM C-642 of all the mix designs is shown in Figure 4. Mix Design E shows the maximum water absorption as compared to the other mix designs followed by mix designs A, F, G, H and I. Silica fume on the other hand proved to be an effective means of reducing absorptivity, despite its small portion replacement of cement ( $8 \%$ to $10 \%)$ in mix designs B and C. Slag, that is effective when it replaces the cement in a large proportion, also showed a considerable decrease in absorptivity. Calcium Nitrate did not seem to affect the absorption property of concrete. Use of air entrainer contributed in reducing the absorption capacity when exposed to marine environment as can be seen in mix designs $\mathrm{H}$ and I as compared to the control mix design $\mathrm{A}$.

\subsection{Corrosion rate test}

The half-cell potential was noted with the half-cell submerged setup, developed in accordance to ASTM C876. The corrosion potential of steel embedded in concrete, exposed to a chloride aggressive environment of $5 \% \mathrm{NaCl}$ for a period of 35 days, showed the mutually comparable rate of corrosion of steel in reinforced concrete due to salt attack, presented in Figure 5. It is clearly visible that the corrosion potential, that represents the corrosion activity in concrete specimen, decreased adequately with the use of pozzolans. Silica fume alone and in combination with fly ash reduced the potential by a wider margin as can be noticed for mix designs $\mathrm{C}$ and $\mathrm{F}$. Use of calcium nitrate as corrosion inhibitor helped in delaying the corrosion process, a great deal. A significant low corrosion activity was witnessed in the concrete samples containing calcium nitrate. 


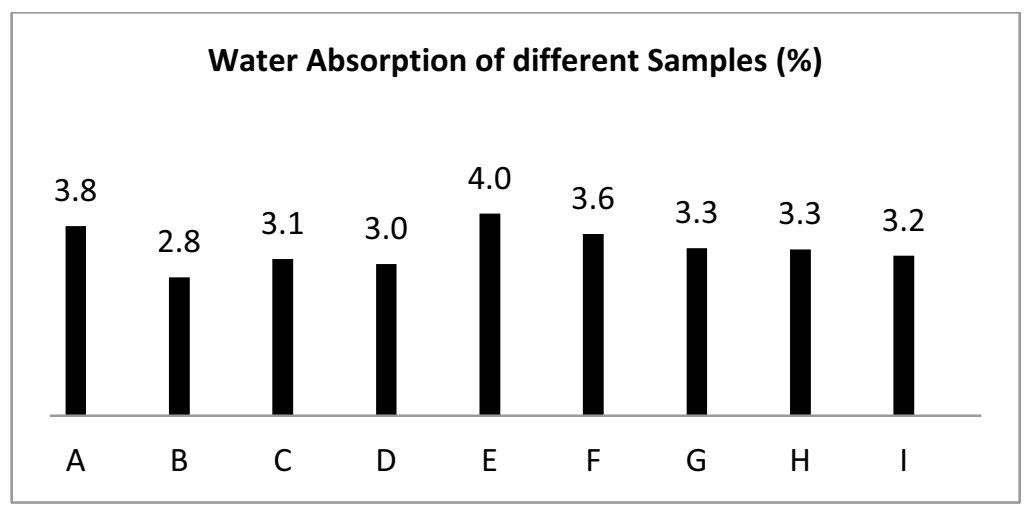

Fig. 4. Absorptivity for Different Mix Design

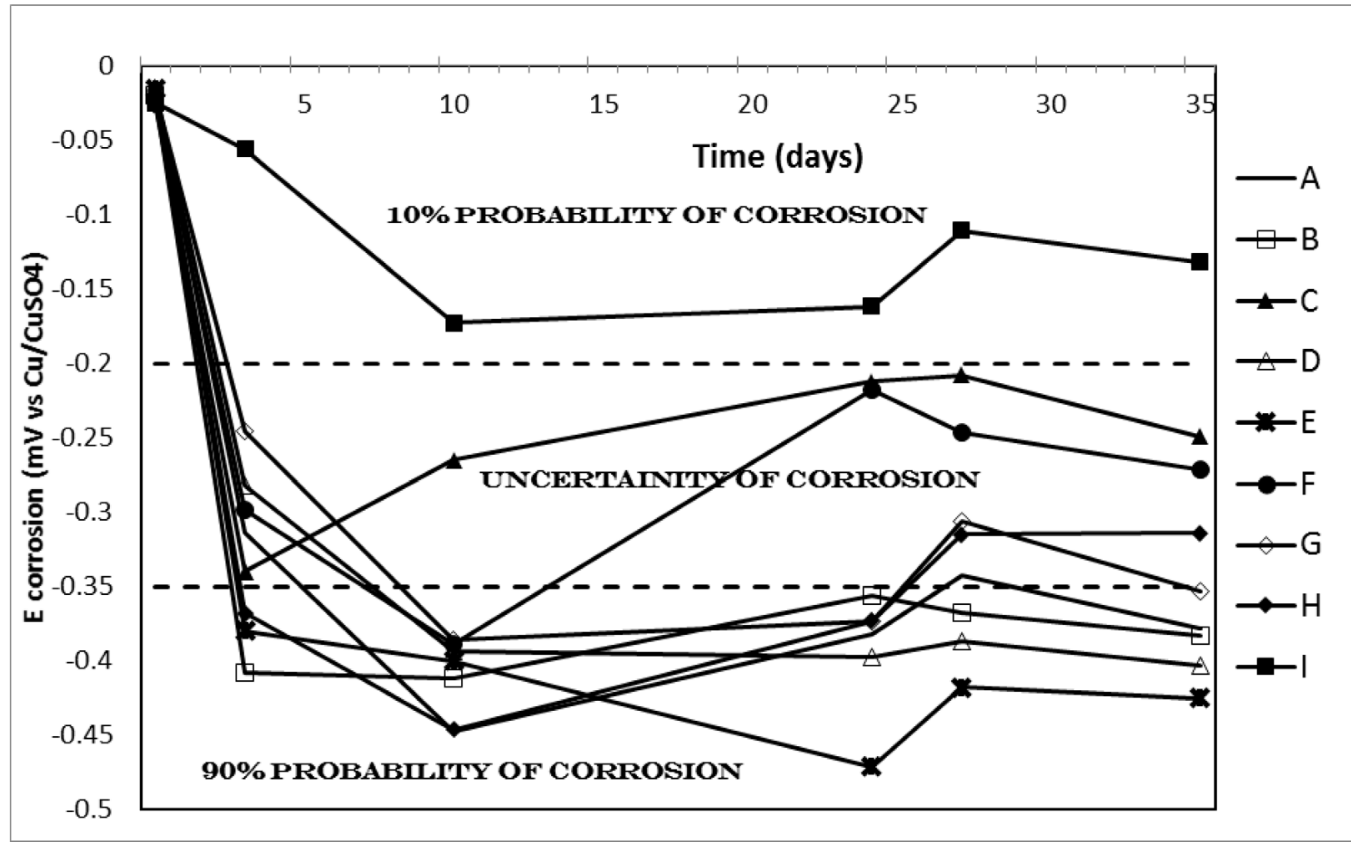

Fig. 5. Variation of Half-Cell Corrosion Potential of Reinforcement versus Time of exposure to Chloride Attack $(5 \% \mathrm{NaCl})$

\section{Conclusions}

Following conclusions can be drawn from the study:

1. Performance of all the mix designs in terms of strength gain were better or comparable to control mix design except for mix designs $\mathrm{E}, \mathrm{F}$ and $\mathrm{G}$ where fly ash was used separately or with silica fume and slag. This may be attributed to slow strength gain of fly ash which also affected the performance of silica fume and slag.

2. Resistance to chloride migration was best observed for the mix design G followed by D and $\mathrm{F}$ indicating that slag only or combination of slag, silica fume and fly ash can produce dense, impermeable and durable concrete. 
3. Least absorption capacity was observed for the mix designs B and D followed by C and I reflecting better performance of Slag and silica fume as compared to fly ash which again shows highest absorption capacity which is even higher than the control mix design A.

4. Performance of mix design I, with calcium nitrate as corrosion inhibiter, was the best in Half Cell corrosion rate measurements followed by mix designs $\mathrm{C}, \mathrm{F}, \mathrm{H}$ and $\mathrm{G}$. Performance of fly ash alone was again not comparable to mix designs with slag and silica fume.

5. As per observed durability results, use of silica fume in combination with slag would be a preferred option in marine concrete within their optimal ranges as defined in the literature. Addition of calcium nitrate as corrosion inhibitor is expected to produce better performance in resisting corrosion.

The authors are indebted to the Department of Civil Engineering at NED University of Engineering \& Technology, Karachi, Pakistan and the University itself, in the pursuit of this work. Authors also gratefully acknowledge the assistance and support provided by the Shahzeb Baloch, Afnan Waseem, Syed Ashad Ali, Osama Hussain, Haris Ali Abbasi, Abdur Rafae.

\section{References}

1. G.J. Verbeck, ACI SP-49 (American Concrete Institute, Detroit, United States, 1975)

2. S.Z. Philip, Offshore Mediterranean Conference and Exhibition, (Ravenna, Italy, 2007)

3. A.R. Khan, T. Zahra, Civil Engineering for Sustainability and Resilience International Conference, CESARE '14 (Amman, Jordan, 2014)

4. A.R. Khan, M.J. Anis, M.S. Ahmed, Second International Conference on Performancebased and Life-cycle Structural Engineering, PLSE 2015 (Brisbane, Australia, 2015)

5. A.R. Khan, M.S. Ahmed, fib Symposium 2016, Performance-based Approaches for Concrete Structures (Cape Town, South Africa, 2016)

6. ASTM C 39 (American Society of Testing and Materials, 2004)

7. ASTM C 293 (American Society of Testing and Materials, 2002)

8. NT Build 492 (Nordic Council of Ministers, Espoo, Finland, 1999)

9. ASTM C 642 (American Society of Testing and Materials, 2006)

10. ASTM C 876 (American Society of Testing and Materials, 1987)

11. ACI 211.1 (American Concrete Institute, 1991)

12. ACI-357 (American Concrete Institute, 1997) 